\title{
Metal Ion Binding of The Corynebacterium pseudotuberculosis Diphtheria Toxin Repressor
}

\author{
Carolina Gismene, Angela N Santisteban, Monika A Coronado, Raphael J Eberle* and \\ Raghuvir K Arni*
}

Multiuser Center for Biomolecular Innovation, Department of Physics, State University of São Paulo (UNESP), São Jose do Rio Preto-SP, 15054-000, Brazil

*Corresponding author: Raphael Eberle and Raghuvir K Arni, Multiuser Center for Biomolecular Innovation, Department of Physics, State University of São Paulo (UNESP), São Jose do Rio Preto-SP, 15054-000, Brazil

\begin{tabular}{l} 
ARTICLE INFO \\
\hline Received: 㓞 January 24, 2019 \\
Published: 幽 February 07, 2019
\end{tabular}

Citation: Carolina G, Angela N S, Monika A C, Raphael J E, Raghuvir KA. Metal Ion Binding of The Corynebacterium pseudotuberculosis Diphtheria Toxin Repressor. Biomed J Sci \& Tech Res 14(2)-2019. BJSTR. MS.ID.002513.

\begin{abstract}
The acquisition of iron is essential to facilitate growth of bacterial pathogens. Bacteria using high-affinity iron uptake systems, siderophores, to scavenge iron from the host is regulated by the diphtheria toxin repressor (DtxR). Additionally, DtxR is a global regulator of cell metabolism and regulates the expression of diphtheria toxin in $C$. diphtheriae. The genome of Corynebacterium pseudotuberculosis, a related animal pathogen with $C$. diphtheriae, contain the genes for diphtheria toxin and DtxR. Our study describe the high scale heterologue expression of Corynebacterium pseudotuberculosis DtxR ( $C p$-DtxR) in E.coli, purification, and characterization of the $\mathrm{Fe}^{2+}$ binding using CD spectroscopy.
\end{abstract}

Key words: C. pseudotuberculosis; Dtxr; Heterologue Gene Expression; Purification; Iron Binding

Abbreviations: $C p$-DtxR: $C$. pseudotuberculosis diphtheria toxin repressor; $C d$-DtxR: $C$. Diphteriae diphtheria toxin repressor; CLA: Caseous Lymphadenitis; CD: Circular Dichroism; HTHM: Helix Turn Helix Motif; RMSD: Root Mean Square Deviation; TEV: Tobacco Etch Virus

\section{Introduction}

The acquisition of essential nutrients and ions such as iron is of primordial significance for the growth and development of bacterial pathogens [1]. Since the concentration of free iron in human serum is estimated to be $10-12 \mu \mathrm{M}$, which is much lower than that required for optimal bacterial growth [2], invasive pathogenic bacteria overcome this problem by using inducible, high-affinity iron uptake systems, siderophores, to scavenge iron from the host $[3,4]$. In gram-positive and gram-negative bacteria, the diphtheriae toxin repressor (DtxR) plays a key role in the regulation and production of siderophores and genes involved in the uptake of iron and other transition metals [5-10]. Additionally, DtxR regulates the expression of diphtheriae toxin in $C$. diphtheriae [11]. The threedimensional structure of $C$. diphtheriae DtxR (Cd-DtxR) reveals that it exists as a dimer containing two metal binding sites per monomer $[12,13]$. Several transition metal ions, such as Fe(II), Ni(II), Co(II), $\mathrm{Cd}(\mathrm{II}), \mathrm{Mn}(\mathrm{II})$ and, to some extent, $\mathrm{Zn}(\mathrm{II})$ activate apo- $C d$-DtxR and, the holo-enzyme binds its target DNA and blocks the transcription of the downstream genes [14-17]. Yellaboina et al. [6] predicted more than 70 DtxR-regulated operons in the C. diphtheriae genome and demonstrated that DtxR is a global regulator of cell metabolism.

Our study was performed on DtxR of Corynebacterium pseudotuberculosis, a related pathogen of Corynebacterium diphtheriae. Analysis of the C. pseudotuberculosis genome identified diphtheriae toxin and DtxR genes. However, diphtheriae toxin is not involved in the C. pseudotuberculosis infection. We assume that DtxR in $C$. pseudotuberculosis mainly plays a role in divalent ion uptake and in the regulation of metabolism. C. pseudotuberculosis causes caseous lymphadenitis (CLA) in equids, sheep, goats, and to a lesser extent in horses and cattle. This disease leads to considerable economic loss in many countries, including Brazil $[18,19]$ and presently, no effective treatment is available to combat this disease. Based on its key role in pathogen cell metabolism, $C p$-DtxR can be considered as a potential drug target and we present results of the expression, purification and characterization of $C p$-DtxR and the iron binding by $\mathrm{Cp}$-DtxR apo-protein.

\section{Material and Methods}

In Silico Analysis: $C p$-DtxR and $C d$-DtxR sequences were retrieved from $\mathrm{NCBI}$ and a sequence alignment were performed using MUSCLE [20] and Box Shade web servers. The atomic coordinates from $C$. diphtheriae DtxR (PDB code: 1G3S) were used as the template for comparative modeling by the satisfaction of spatial restraints as implemented in the program Modeller 9v13 [21]. The structure of native Cp-DtxR (Gene ID: ADL10687.1; Uniprot: D9QAW1) was modeled. 
Expression and Purification of DtxR: The open reading frame of $C p$-DtxR was cloned into the vector pD441-SR by DNA 2.0 (USA). The construct contains an N-terminal TEV cleavage site and hexahistidine affinity tag. The kanamycin-resistant vector pD441SR presents a T7 promoter inducible by IPTG and a high copy percentage provided by pUC origin of replication. DtxR-pD441-SR (DNA 2.0) vectors were transformed into E. coli BL21 (DE3)T1 (Sigma-Aldrich, USA) competent cells, which were grown for $16 \mathrm{~h}$ (overnight) at $37^{\circ} \mathrm{C}$ in $\mathrm{LB}$ medium containing sufficient amounts of kanamycin. The bacterial cultures were transferred into fresh LB medium, grown for another $3.0 \mathrm{~h}$ at $30^{\circ} \mathrm{C}$ until the $0 D 600$ reached 0.6 . Subsequently, $C p$-DtxR expression was induced by $0.4 \mathrm{mM}$ IPTG, and incubated for $4 \mathrm{~h}$ at $30^{\circ} \mathrm{C}$, being supplemented with 50 $\mu \mathrm{M} \mathrm{FeCl}_{2}$. Later, the culture was harvested by centrifugation at 4000 g, $5^{\circ} \mathrm{C}$ for $20 \mathrm{~min}$, discarding the supernatant and re-suspending the $C p$-DtxR containing cell pellet in $20 \mathrm{mM} \mathrm{K}_{2} \mathrm{HPO}_{4} / \mathrm{KH}_{2} \mathrm{PO}_{4} \mathrm{pH}$ 7.4, $500 \mathrm{mM} \mathrm{NaCl}, 5 \%$ (v/v) glycerol, $2 \mathrm{mM}$ imidazole.

The cell-suspension was incubated on ice for $1 \mathrm{~h}$ with lysozyme, subsequently being lysed by sonication in four sets of $30 \mathrm{~s}$ pulses of $30 \%$ amplitude, with $10 \mathrm{~s}$ intervals. This way obtained crude cell extract was centrifuged at $8000 \mathrm{~g}, 6^{\circ} \mathrm{C}$ for $90 \mathrm{~min}$. The supernatant containing $C p$-DtxR was loaded onto Ni-NTA column preequilibrated with $20 \mathrm{mM} \mathrm{K}_{2} \mathrm{HPO}_{4} / \mathrm{KH}_{2} \mathrm{PO}_{4} \mathrm{pH} 7.4,500 \mathrm{mM} \mathrm{NaCl}, 5 \%$ (v/v) glycerol, $2 \mathrm{mM}$ imidazole, extensively washed with the same buffer containing 20 and $60 \mathrm{mM}$ imidazole, $C p$-DtxR eluted with $300 \mathrm{mM}$ imidazole. The eluted fractions were individually pooled and injected onto a Superdex 75 10/300 GL size exclusion column (GE Healthcare), pre-equilibrated with buffer $20 \mathrm{mM} \mathrm{K}_{2} \mathrm{HPO}_{4}$ / $\mathrm{KH}_{2} \mathrm{PO}_{4} \mathrm{pH} 7.4,150 \mathrm{mM} \mathrm{NaCl}$. Sample purity after each purification step was assessed by 15\% SDS-PAGE gels. Fractions containing $C p$-DtxR were concentrated in a micro concentrator (MWCO: 3000Da, GE Healthcare). Protein concentrations were determined spectrophotometrically, applying the Lambert-Beer law [22].

\section{Spectroscopy:}

For all CD measurements, 15 repeated scans were performed, 5 scans were used to establish the baseline. The wavelength range applied for far-UV spectra was from $200 \mathrm{~nm}$ to $260 \mathrm{~nm}$, in a time constant of $1 \mathrm{~s}$ and $100 \mathrm{~nm} /$ min continuous scanning mode, using a Jasco J-107 spectropolarimeter (Jasco, Japan). Prior to conducting the CD experiments, $C p$-DtxR was incubated overnight with $1 \mathrm{mM}$ EDTA, to remove irons from the specific binding sites. EDTA and EDTA-ion complexes were eliminated by dialysis against $20 \mathrm{mM}$ $\mathrm{K}_{2} \mathrm{HPO}_{4} / \mathrm{KH}_{2} \mathrm{PO}_{4} \mathrm{pH}$ 7.0. Cp-DtxR was diluted to a concentration of 1 $\mu \mathrm{M}$. The effect of the iron ions was tested on the protein secondary structure. The protein was pre-incubated with $10 \mu \mathrm{M} \mathrm{Fe}^{2+}$ for one hour prior to the measurements. The results are presented in molar ellipticity $[\theta]$, according to: in which, $\theta$ is the ellipticity measured at a given wavelength $\lambda(\mathrm{deg}), \mathrm{c}$ is the protein concentration $\left(\mathrm{mol} \mathrm{L}^{-1}\right)$, $l$ is the cell path length $(\mathrm{cm})$ and $\mathrm{n}$ is the number of amino acids. CDpro software package was adopted to analyze the results [23].

\section{Results and Discussion}

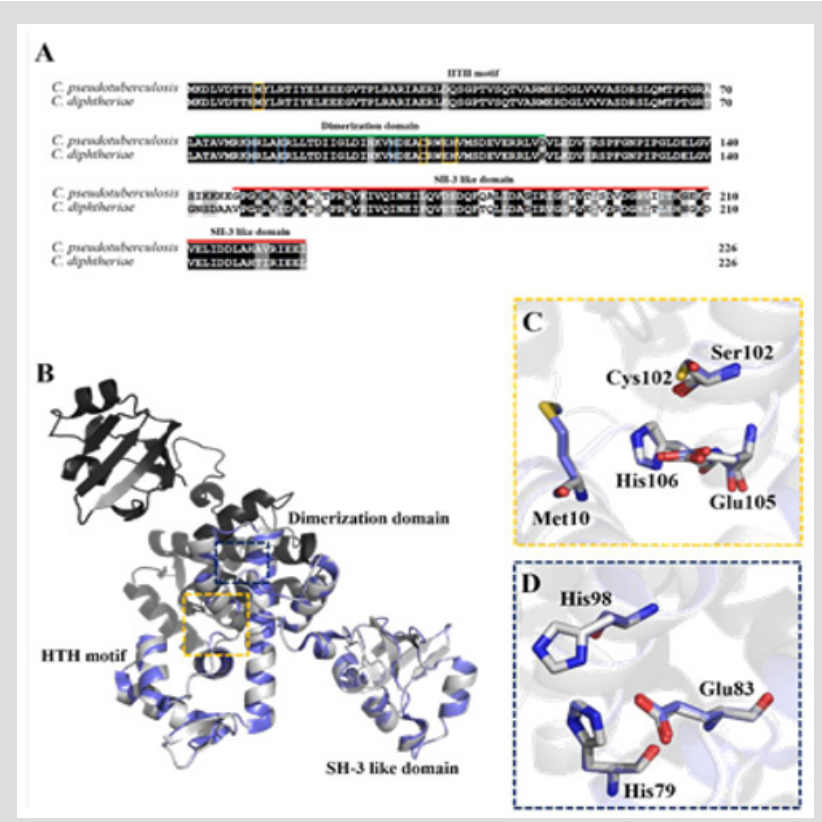

Figure 1: Sequence alignment and structural comparison of $C p$-DtxR and $C d$-DtxR.

a. Sequence alignment of $C p$-DtxR and $C d$-DtxR. DtxR domains: HTH motif (grey bar), dimerization domain (green bar) and SH-3 like domain (red bar). Yellow boxes mark the residues coordinating metal binding site 1, blue boxes mark the residues coordinating metal binding site 2 .

b. Structural comparison of $C p$-DtxR homology model (in grey) as dimer and Cd-DtxR crystal structure (PDB: 1G3S in blue). The domains are shown and the both ion-binding sites in the monomer are highlighted.

c. Amino acids coordinating metal binding site 1 .

d. Amino acids coordinating metal binding site 2 . 
Sequence Alignment and Molecular Model of $\mathrm{Cp}$ DtxR: A BLAST search for the $C p$-DtxR sequence against the nonredundant protein sequences database [24] indicated that the protein sequence is highly conserved within the Corynebacterium genus (75\% to 95\%) (Figure 1A). A Blast search for the $C p$-DtxR sequence against the data deposited with the Protein Data Bank showed a sequence identity of $78 \%$ with the $C d$-DtxR protein structure (PDB: 1G3S), which was used to generate a $C p$-DtxR model. The DtxR proteins are dimers and contain three highly conserved domains important for the protein function, which is characteristic of the protein family $[12,13]$. The HTH motif is important for DNA binding. The SH3-like domain shows more differences in the protein sequence (Figures 1A \& 1B); however, the residues coordinating the metal binding sites 1 and 2 are conserved within the two species (Figures 1A-1D). The structural overlay of the $C p$-DtxR model and the $C d$-DtxR crystal structure resulted in an rmsd value of 0.135 (1433 atoms) and indicates the significant conservation of the protein structure within the Corynebacterium family.

Protein production and purification: The $C p$-DtxR construct consists of 239 amino acids (including TEV cleavage site and hexa-histidine tag) with a molecular weight of 26.877 Da. The protein presented a single band on a denaturing SDS-PAGE gel (Figure 2) with an apparent molecular mass of approximately $30.000 \mathrm{Da}$, after the two-step purification (Figure 2). The size exclusion chromatography demonstrated that the protein exists in solution as a dimer, which was confirmed with a SEC calibration (supplementary Figure 1).

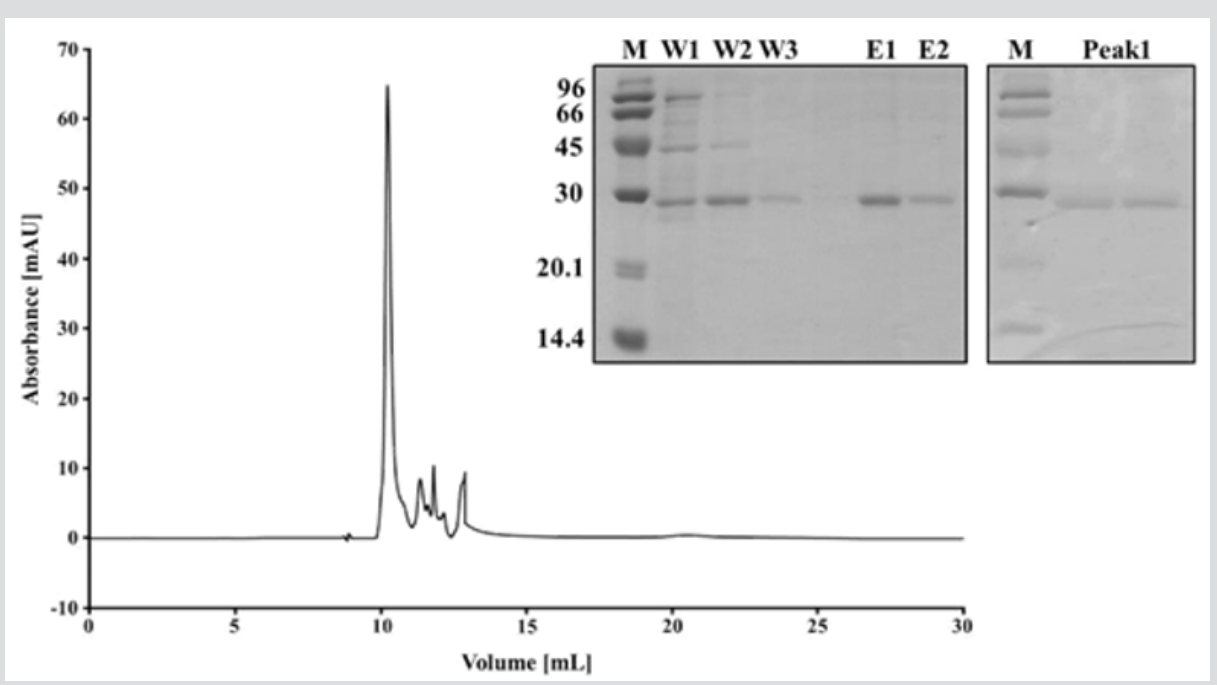

Figure 2: Purification of $C p$-DtxR. SDS-PAGE analysis of $C p$-DtxR after Ni-NTA purification. M: protein marker, $\mathrm{W}_{1-3}$ : washing steps, $\mathrm{E}_{1-2}$ : elution steps.SDS-PAGE of $\mathrm{C} p$-DtxR after size exclusion chromatography, which indicate the purity of the protein. Chromatogram of size exclusion chromatography of $C p$-DtxR, elute at around $10.5 \mathrm{ml}$, which corresponds to a dimer of $C p$ DtxR.
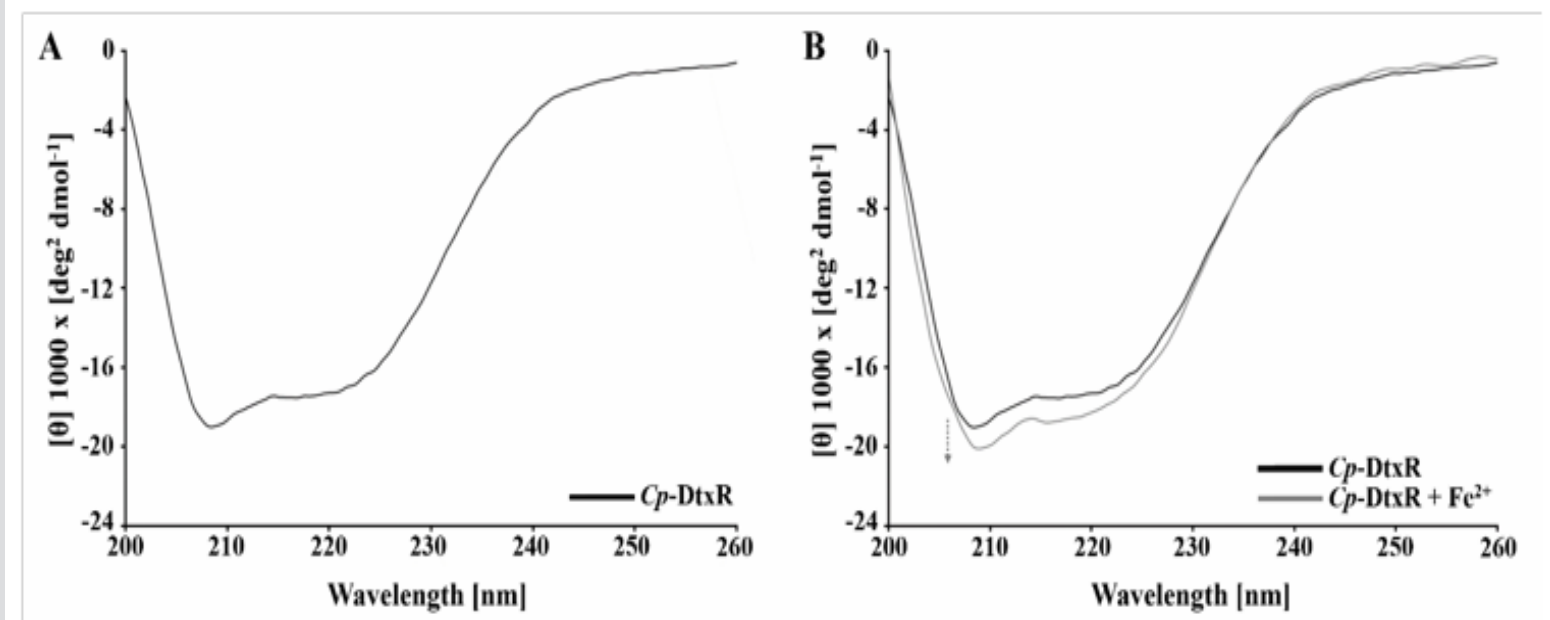

Figure 3: Conformational changes in the $C p$-DtxR secondary structure studied by CD spectroscopy.

A: CD spectra of Cp-DtxR incubated with EDTA. B: Overlay of the CD-spectra from Cp-DxtR incubated with EDTA and after treated with $\mathrm{Fe}^{2+}$. 


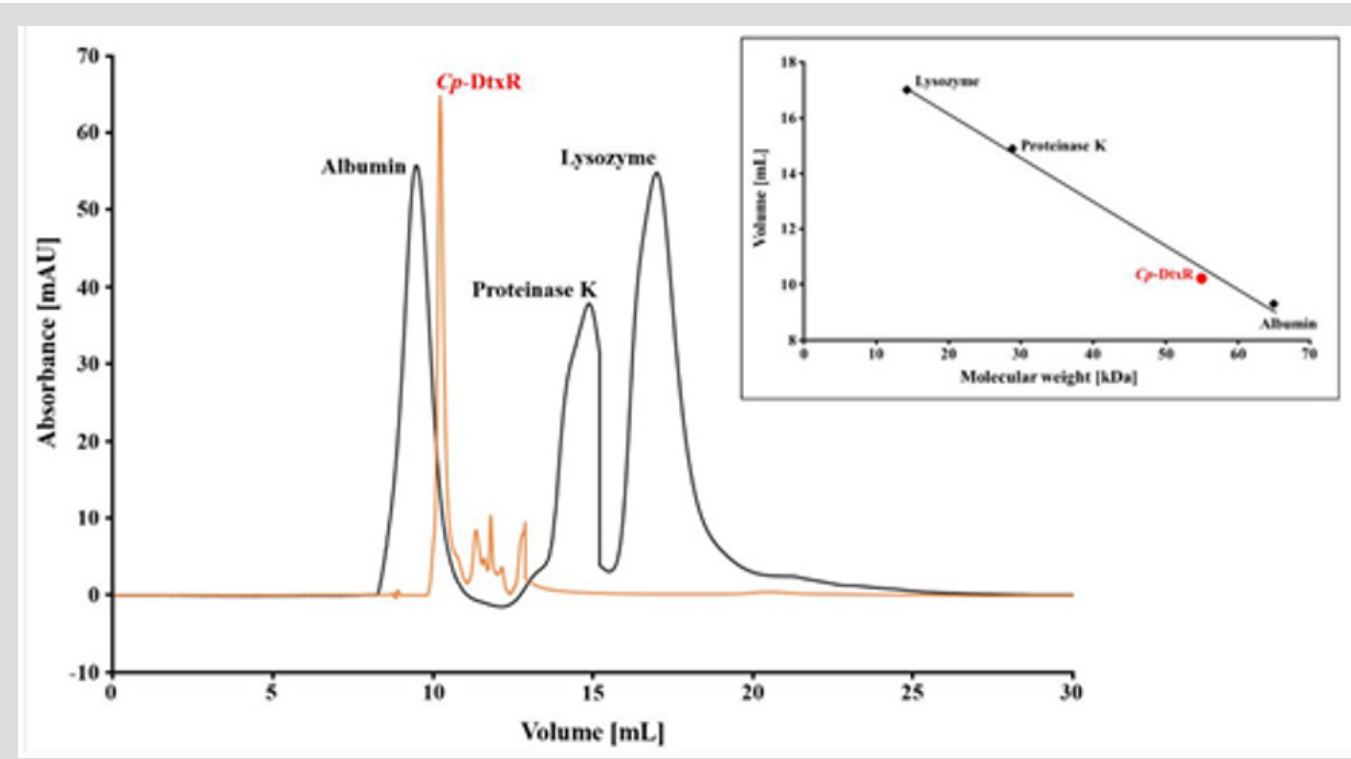

Figure S1: Calibration of the SEC column used for the Cp-DtxR purification. The chromatogram show the elution peaks of Albumin $(65 \mathrm{kDa})$, Proteinase K (29.7 kDa) and Lysozyme (14.3 kDa). Cp-DtxR elute at around $10.5 \mathrm{ml}$, the protein monomer has a MW of around $27 \mathrm{kDa}$, but the protein elute as dimer, near a MW of $60 \mathrm{kDa}$ as demonstrated in the linear elution plot.

CD spectroscopy: Protein conformational changes induced by iron ions were monitored using far-UV CD spectroscopy. Thereby the effect of $\mathrm{Fe}^{2+}$ binding to apo- $\mathrm{Cp}$-DtxR were investigated (Figure 3 ). The results of the secondary structure prediction of $C p$-DtxR by CDpro [23] based on the results of the far-UV CD measurements indicated 34\% $\alpha$-helices, $61 \%$ random coiled regions and $5 \%$ $\beta$-sheet in the protein secondary structure. The results indicated a high $\alpha$-helical and random coiled content in the secondary of the protein, these results are in agreement with the existing 3D structures of DtxR proteins for example from C.diphtheriae(PDB: 1G3S), $43 \% \alpha$-helices and $14 \% \beta$-sheet. Secondary structural change due to $\mathrm{Fe}^{2+}$ binding was observed and analyzed using the CDpro software [23]. The results demonstrated that following $\mathrm{Fe}^{2+}$ binding, an increase in the $\alpha$-helical content (34\% to $38 \%$ ) of the protein secondary structure is observed. Local structural rearrangements following metal ion binding to apo-DtxR have been correlated with helix-to coil transitions [25], which are in close agreement with our $\mathrm{CD}$ results.

\section{Conclusion}

The diphtheriae toxin repressor from $C$. diphtheriae is an intensively investigated cellular protein. The protein controls diphtheriae toxin production and the production of siderophores and is a global regulator of the cell metabolism. C. pseudotuberculosis is a related pathogen of $C$. diphtheriae and contains the diphtheriae toxin and DtxR genes, but diphtheriae toxin is not considered to be directly involved in the infection mechanism of C. pseudotuberculosis rather, DtxR seems to play regulatory function in the transition metal uptake and the cell metabolism. The function and importance of $C$. pseudotuberculosis DtxR remains poorly understood and research in this area can contribute to narrow the search for molecular targets against caseous lymphadenitis.Our results describe for the first time a protocol for the heterologous gene expression of $C p$-DtxR in E.coli cells and a subsequent two-step purification process. The production of protein in a high amount and quality are necessary for further investigations of $C p$-DtxR.

\section{Acknowledgement}

This research was supported by grants from CNPq [Grant numbers 435913/2016-6, 401270/2014-9, 307338/20142, 150444/2017-6], FAPESP [Grant numbers 2015/13765-0, 2015/18868-2, 2016/12904-0; 2009/53989-4], CAPES and PROPe UNESP.

\section{References}

1. Litwin CM, Calderwood SB (1993) Role of iron in regulation of virulence genes. Clin Microbiol Rev 6(2): 137-149.

2. Bullen JJ, Rogers HJ, Griffiths E (1978) Role of iron in bacterial infection. Curr Top Microbiol Immunol 80: 1-35.

3. Bagg A, Neilands JB (1987) Molecular mechanism of regulation of siderophore-mediated iron assimilation. Microbiol Rev 51: 509-518.

4. Neilands JB (1982) Microbial envelope proteins related to iron. Annu Rev Microbiol 36: 285-309.

5. Qian Y, Lee JH, Holmes RK (2002) Identification of a DtxR regulated operon that is essential for siderophore-dependent iron uptake in Corynebacterium diphtheriae. J Bacteriol 184: 4846-4856.

6. Yellaboina S, Ranjan S, Chakhaiyar P, Hasnain SE, Ranjan A, et al. (2004) Prediction of DtxR regulon: identification of binding sites and operons controlled by diphtheriae toxin repressor in Corynebacterium diphtheriae. BMC microbiology 4(1): 38.

7. Jakubovics NS, Smith AW, Jenkinson HF (2000) Expression of the virulence-related Sca $\left(\mathrm{Mn}^{2+}\right)$ permease in Streptococcus gordonii is regulated by a diphtheriae toxin metallorepressor-like protein ScaR. Mol Microbiol 38(1): 140-153.

8. Patzer SI, Hanke K (2002) Dual repression by Fe2+-Fur and Mn2+ MntR of the montH gene, encoding an NRAMP-like Mn2+ transporter in Escherichia coli. J Bacteriol 183: 4806-4813.

9. Que Q Helmann JD (2000) Manganese homeostasis in Bacillus subtilis is regulated by MntR, a bifunctional regulator related to the diphtheriae toxin repressor family of proteins. Mol Microbiol 35(6): 1454-1468. 
10. Schmitt MP, Predich M, Doukhan L, Smith I, Holmes R (1995) Characterization of an iron-dependent regulatory protein (IdeR) of Mycobacterium tuberculosis as a functional homolog of the diphtheriae toxin repressor (DtxR) from Corynebacterium diphtheriae. Infect Immun 63: 4284-4289.

11. Pappenheimer AM (1977) diphtheriae toxin. Annu Rev Biochem 46: 6994.

12. Qiu X, Verlinde CL, Zhang S, Schmitt MP, Holmes RK, et al. (1995) Threedimensional structure of the diphtheriae toxin repressor in complex with divalent cation co-repressors. Structure 3(1): 87-100.

13. Ding X, Zeng H, Schiering N, Ringe D, Murphy JR (1996) Identification of the primary metal ion-activation sites of the diphtheriae tox represser by X-ray crystallography and site-directed mutational analysis. Nat Struct Mol Biol 3(4): 382.

14. Tao X, Murphy JR (1992) Binding of the metalloregulatory protein DtxR to the diphtheriae tox operator requires a divalent heavy metal ion and protects the palindromic sequence from DNase I digestion. J Biol Chem 267(30): 21761-21764.

15. Schmitt MP, Holmes RK (1993) Analysis of diphtheriae toxin repressoroperator interactions and characterization of a mutant repressor with decreased binding activity for divalent metals. Mol Microbiol 9(1): 173181.

16. Boyd JM, Oza M, Murphy JR (1990) Molecular cloning and DNA sequence analysis of a diphtheriae-tox iron-dependent regulatory (dtxR) element from Corynebacterium diphtheriae. Proc Natl Acad Sci USA 87: 59685972.

ISSN: 2574-1241

DOI: 10.26717.BJSTR.2019.14.002513

Raphael J Eberle.Biomed J Sci \& Tech Res

(C) This work is licensed under Creative Commons Attribution 4.0 License

Submission Link: https://biomedres.us/submit-manuscript.php
17. Schmitt MP, Holmes RK(1991) Characterization of a defective diphtheriae toxin repressor (dtxR) allele and analysis of $d t x R$ transcription in wildtype and mutant strains of Corynebacterium diphtheriae. Infect Immun 59: 3903-3908.

18. Dorella FA, Pacheco LG, Oliveira SC, Miyoshi A, Azevedo V, et al. (2006) Corynebacterium pseudotuberculosis: microbiology, biochemical properties, pathogenesis and molecular studies of virulence. Vet Res 37: 201-218.

19. Ayers JL (1997) Caseous lymphadenitis in goats and sheep: a review of diagnosis, pathogenesis, and immunity. J Am Vet Med Assoc 171: 12511254.

20. Edgar RC (2004) MUSCLE: a multiple sequence alignment method with reduced time and space complexity. BMC bioinformatics 5(1): 113.

21. Eswar N, Webb B, Marti-Renom MA, Madhusudhan MS, Eramian D, et al. (2006) Comparative protein structure modeling using Modeller. Curr Protoc Bioinformatics 15(1): 5-6.

22. Grimsley GR, Pace CN (2004) Spectrophotometric determination of protein concentration. Curr Protoc Protein Sci 3: 1-3.

23. Sreerama N, Woody RW (2004) Computation and analysis of protein circular dichroism spectra. Meth Enzymol 383: 318-351.

24. Altschul SF, Gish W, Miller W, Myers EW, Lipman DJ, et al. (1990) Basic local alignment search tool. J Mol Biol 215: 403-410.

25. White A, Ding X, Murphy JR, Ringe D (1998) Structure of the metal-ionactivated diphtheriae toxin repressor/tox operator complex. Nature 394(6692): 502 .

\begin{tabular}{ll} 
BIOMEDICAL & Assets of Publishing with us \\
RESEARCHES & - Global archiving of articles \\
\hline ISSN: $2574-1241$ & - Immediate, unrestricted online access \\
\hline
\end{tabular}

